\title{
An alternative data driven approach for prediction of thermal discharge initial dilution using tee diffusers
}

\author{
*A. Etemad-Shahidi; M. J. Zoghi; M. Saeedi
}

School of Civil Engineering, Iran University of Science and Technology, Tehran, Iran

Received 4 February 2009; revised 19 July 2009; accepted 10 November 2009; available online 1 December 2009

\begin{abstract}
Mixing of heated water discharged from outfalls is an efficient and effective method of waste disposal in coastal areas. Discharging the heated water with large quantities of mass flux generally requires multi-port diffusers. In recent years, using numerical models to predict the plume behavior has received attention from many researchers, who are interested in design of outfalls. This study reports the development and application of an artificial neural network model for prediction of initial dilution of multi-port tee diffusers. Several networks with different structures were trained and tested using error back propagation algorithm. Statistical error measures showed that a three layer network with 9 neurons in the hidden layer is skillful in prediction of initial dilution and the outputs are in good agreement $(\mathrm{R}=0.97)$ with experimental results. Furthermore, the sensitivity analyses showed that the width of the equivalent slot of the diffuser is the most important parameter in the estimation of initial dilution.
\end{abstract}

Keywords: Mixing; Neural network; Ocean outfalls; Thermal discharge

\section{INTRODUCTION}

Pollutants discharging into marine and coastal waters can be classified based on their origin as natural and anthropogenic. Anthropogenic originated pollutions are mainly discharged from inland as domestic and industrial wastewaters, either via marine outfalls or rivers. A marine outfall is a mean for discharging industrial wastewater, storm runoff or sewage out to undersea disposal point. Outfalls mostly involve pipes laid in or on the seabed. The discharge of sewage can be made by a variety of ways, ranging from a single to multiport diffusers. Submerged multiport diffusers are generally considered to be the most efficient means of fast dilution of discharged heat. A multiport diffuser is a linear diffusion structure consisting of a manifold which contains numerous closely spaced ports through which heated water is discharged as in the form of a turbulent jet into the receiving water at high velocity. A tee diffuser is a diffuser which its alignment is parallel to the ambient cross flow.

Adverse effects of thermal discharges on marine environment (i.e. coral reefs, beaches, coasts and estuaries) have been reported in previous works

*Corresponding Author Email: etemad@iust.ac.ir Tel.: +9821 7724 0399; Fax: +982177240398
(Alesheikh et al., 2007; Karuppanapandian et al., 2007; Nouri et al., 2008; Cetin, 2009). Abbaspour et al. (2005) attempted to model thermal pollution in Persian Gulf in the vicinity of a thermal power plant. They also evaluated its environmental and economic effects. Regarding thermal discharges environmental and coastal economic effects, developing alternative methods to predict thermal discharges dilution in marine environments seems to be very important.

By discharging the heated water through a large number of ports at a high velocity, the total area available for jet entrainment is increased, permitting the rapid dilution of the discharged water (Kim and Seo, 2000).

The design and construction of marine outfalls require both economic and human efforts. It is therefore necessary to assure the perfect performance of the outfall, either by constructing a physical model of the layout or using numerical models. Physical modeling usually is a time consuming task and is limited to technical constraints. On the other hand, numerical modeling allows simulation of a great number of scenarios and can be used more effectively for the optimal design. These models, however, need to be verified using measurements either in the field or in the laboratory (Falconer, 1992). 
Heated water discharged from power plants can increase the ambient water temperature. This process can negatively affect the coastal environment. According to the environmental standards, the maximum increase in ambient temperature due to the thermal discharges shall not exceed $2{ }^{\circ} \mathrm{C}$ (Elsayed, 1981). Using multi-port diffusers can reduce the maximum temperature rise and protect coastal environments.

Due to the large number of variables affecting the behavior of an outfall discharge into a waterbody, determination of the initial dilution and other characteristics of the resulting wastefield are not easy tasks. Hence, available studies and analyses in the literature are mostly concerned with simplified and limiting cases. Öztürk et al. (1995) developed a twodimensional simplified model in order to estimate the distribution of temperatures in the marine environment following the discharge of thermal effluents. The model has been successfully used in environmental impact assessment studies of the two $500 \mathrm{MW}$ power plants proposed at the east of Marmara Sea, Turkey. Hamrick and Mills (2000) developed a three-dimensional surface water model system capable of addressing a variety of power plant impact issues, including thermal transport, in surface water systems.

Hybrid techniques also have been used to simulate the dispersion of heat from surface discharges in coastal areas. Very reasonable agreement was reported applying a hybrid near-field/far-field thermal discharge model for coastal areas using CORMIX3 for the nearfield thermal dispersion, two-dimensional harmonic finite element hydrodynamic model (TEA) and an Eulerian-Lagrangian transport model (ELA) for the farfield computation (Suh, 2001).

The usual approach in many studies is to apply dimensional analysis and length scale arguments, based on fluxes of momentum, volume and buoyancy. Then the results are compared with data obtained from field measurements or from controlled lab experiments. Rapid dilution in water bodies depends on three parameters, nature of the outfall, the characteristics of the receiving water and the constituents of the raw sewage (Fischer et al., 1977). Numerical models can predict the behavior of plume dilution. Several numerical models are presently available for the prediction of initial dilution from thermal discharges. Mixing zone models were developed in three major categories: Three-dimensional finite element or finite difference models, integral-type models and length-scale models. In the first category, the system of equations of motion is solved via numerical techniques that require large computational time. The last two categories are often called zone models, because the region of interest is divided into several zones with distinct properties.

Several numerical models are presently available to engineers for the hydraulic design of outfalls. These models are traditionally classified as length scale models such as CORMIX (Akar and Jirka, 1991), integral type models such as VISJET (Lee and Cheung, 1990) and 3 D models (Kim and Seo 2000). The performances of these models have been evaluated using filed and laboratory experimental data (Etemad-Shahidi et al., 2006, Etemad-Shahidi and Azimi, 2007). Artificial neural networks (ANN) has been developed and used for engineering purposes (Muttiah et al., 1997; Maier and Dandy, 2000; Huang and Foo, 2002; Suen and Eheart, 2003, Mahjoobi et al., 2008; Etemad-Shahidi and Mahjoobi, 2009, Kazeminezhad et al., 2010). In the filed of environmental engineering, ANNs have been used for prediction of water quality in coastal and inland waters (Suen and Eheart 2003; Kuo et al., 2007; Palani et al. 2008). ANN models have not been used for outfall design yet. The aim of this study is to examine the performance of the ANN modeling for the prediction of initial dilution in a complex environment, i.e. tee diffuser in ambient current. Here, the results of ANN modeling and some empirical equations are compared to that those of a physical model of multi-port tee diffusers.

In this study, data set collected by Seo et al. (2001) for tee diffusers was used to develop the ANN model for prediction of initial dilution. Two third of the collected data points were selected randomly for training of the models and the remaining part was used for models' validation. This numerical experiment was conducted in the School of Civil Engineering, Iran University of Science and Technology, during 20072008.

\section{MATERIAL AND METHODS}

A neural network is best defined as a set of simple, highly interconnected processing elements that are capable of learning information. A neural network's ability to learn and process information classifies it as a form of artificial intelligence. After McCulloch and Pitts (1943) introduced the concept of a neural network, many ANN models have been developed (Rumelhart et al., 1986, Grossberg 1988). The multi-layered network trained by back-propagation algorithm is mostly applied 
for solving different engineering problems recently (Yeh et al., 1993, Bateni et al., 2007). Supervised training is required for back propagation related problems. In back propagation type neural networks, information is processed in interconnecting processing elements or nerons. These nodes are organized into groups termed layers. There are three distinct types of layers in a back propagation neural network: the input layer, the hidden layer (s) and the output layer. All inputs to a node are weighted, combined and then processed through a transfer function that controls the strength of the signal relayed through the node's output connections. The transfer function is used to normalize a output signal strength between 0 and 1 . The sigmoid function is the most widely used function for back propagation neural networks. The errors are determined and back propagated though the network in an attempt to improve the network's response. Amounts determined by the training algorithm are used to adjust the nodal weight factors. The errors are determined by the iterative procedure of processing inputs through the network and the weights constitutes the learning process are adjusted. One training iteration is completed when all supplied training cases have been processed through the network. The training algorithms adjust the weights in an attempt to drive the network's response error to a minimum. The training algorithm's adjustment of the weights are controlled by two factors. They are the "learning rate coefficient” and the "momentum factor".
If the learning rate is too fast, network training can become unstable. If the learning rate is too small, the network will learn at a very slow pace. The momentum factor has a smaller influence on learning speeds, but it can influence training stability and promote faster learning for most networks. Higher values of the momentum factor can help the network escape from local minimum.

The used network in this study was the common three-layered feed forward type of network shown in Fig. 1. In this network, the input nodes receive the input variables (ambient current) and pass them on to the hidden layer nodes. First, the input values are normalized within the range of 0.0-1.0 and multiplied by a weight and summed up in each individual node. Then a bias is added to each sum and it is passed on the result through a non-linearity like a sigmoid transfer function. This forms input to the output layer that operates similar to the hidden layer nodes. The output from each output node is transformed and forms the network output. As followed by Yeh et al. (1993), the error back propagation was employed for training of the network. The goal of the training is to minimize the overall error, $E$, defined below (Deo and Kumar, 2000):

Where, $P=$ total number of training patterns, $E_{p}=$ error for $p$ th training pattern defined as:

$$
E=\frac{1}{P} \sum_{1}^{P} E_{p}
$$

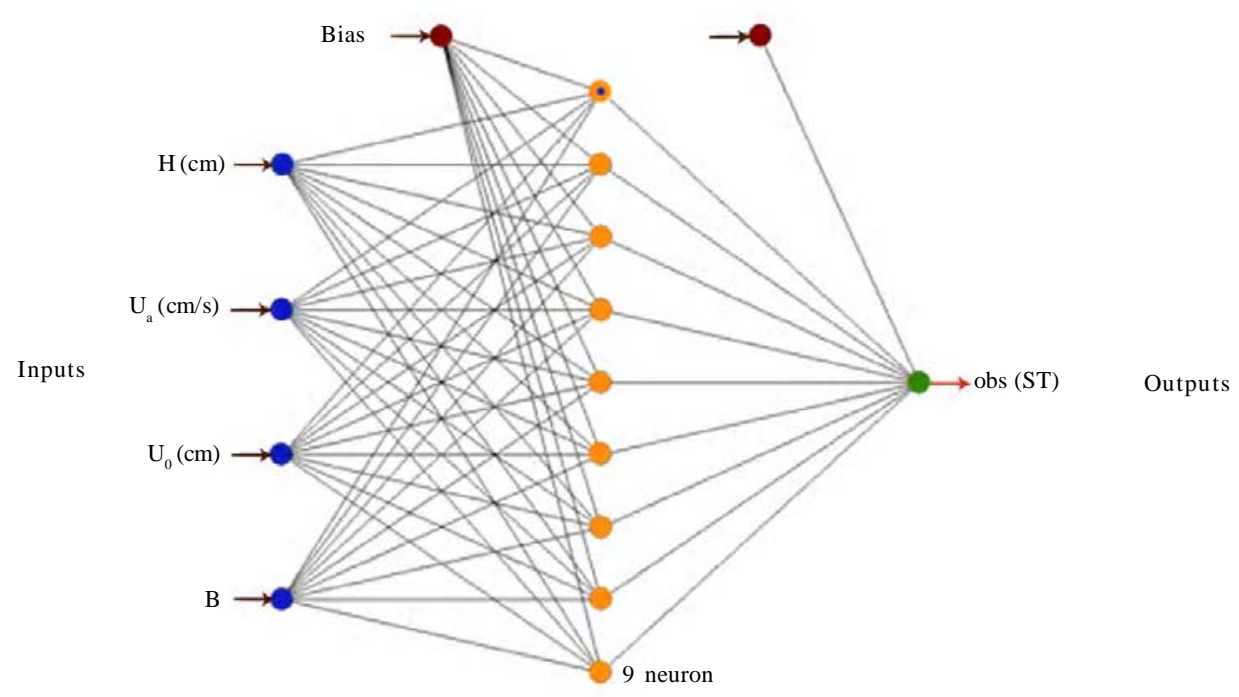

Fig. 1: The structure of used ANN model 


$$
E_{p}=\frac{1}{2} \sum_{0}^{N}\left(o_{k}-t_{k}\right)^{2}
$$

Where, $N=$ total number of output nodes, $o_{k}=$ network output at the $k$ th output node, and $t_{k}=$ target output at the $k^{\text {th }}$ output node.

The scheme of error back-propagation is used to reduce the global error in the training process. This scheme involves minimization of the error between the modeled output and the measured one for each training pattern supplied. Here, steepest descent or gradient descent approach is employed. In each iteration, the network weights and biases are adjusted by moving a small step in the direction of negative gradient of the error function. The iterations are repeated until a specified error or iterations number is achieved. The gradient descent is given by (Deo and Kumar, 2000):

$\bar{X}_{k+1}=\bar{X}_{k+1}-n \bar{g}\left(\bar{X}_{k+1}-1\right)$

Where, $\bar{X}_{k}=$ vector of weights at $k$ th iteration index, $\bar{X}_{k+1}=$ vector of weights at $(k+1)^{\text {th }}$ iteration index, $n=$ step size supplied by the user, $\bar{g}=$ gradient vector

$\bar{g}=\nabla f(\overline{X)}$

and $f(\overline{X)}=$ error function for a general weight vector $\bar{X}$. The above error gradient approach is simple to use. However, it converges slowly and may exhibit oscillatory behavior due to fixed step size. Generally, the numbers of layers and their nodes are determined by trial and error (Eberhart and Dobbins, 1990).

In order to compare different network performances, the following error measures were calculated:

Coefficient of correlation $(R)$ :

$$
R=\frac{\sum\left(x_{i}-\bar{x}\right)\left(y_{i}-\bar{y}\right)}{\sqrt{\sum\left(x_{i}-\bar{x}\right)^{2} \sum\left(y_{i}-\bar{y}\right)^{2}}}
$$

Mean squared error (MSE):

$\mathrm{MSE}=$

$\operatorname{Bias}=$

$$
\frac{1}{n} \sum_{1}^{n}\left(x_{i}-y_{i}\right)^{2}
$$

$$
\bar{y}-\bar{x}
$$

In all formulae, the $x$ 's = measured values, the $y$ 's $=$ predicted values, $\mathrm{n}=$ number of observations, $\bar{x}=$ mean of and $x=$ mean of $y$.

In this study data set collected by Seo et al. (2001) for tee diffusers was used to develop the ANN model for prediction of initial dilution. The objective of their study was to investigate the characteristics of initial dilution over a wide range of momentum ratio conditions. Hence, extensive experimental work was carried out and the initial dilution was measured in the laboratory. The experiments were conducted in a $20 \mathrm{~m}$ long flume and the similitude of densimetric Froude number was used for scaling of the model. The Reynolds similarity was relaxed since the flow was turbulent and near field area was of importance. The total length of the diffusers was $120 \mathrm{~cm}$ while the ports had an inner diameter of $0.43 \mathrm{~cm}$ with a spacing varying between 4.0 to $12.0 \mathrm{~cm}$. These ports had an angle of 22.5 to the channel bottom. The flow was measured by an electromagnetic flow meter and the temperature was measured by CC-type thermo-couple sensors connected to a data logger (Seo et al., 2001). The temperature of the ambient water was $20{ }^{\circ} \mathrm{C}$ while the outfall had a temperature of $30{ }^{\circ} \mathrm{C}$. It was assumed that the flow is vertically well mixed. Three test series were conducted and two third of the collected data points were selected randomly for training the models and the remaining part was used for models' validation.

\section{RESULTS AND DISCUSSION}

As mentioned before, the data set used in this study for prediction of initial dilution is obtained from laboratory experiment of Seo et al. (2001). Here, two third of the data points was used for training while the remaining part was used for validation of the ANN model. Table 1 shows the range of different parameters used for the prediction of initial dilution. Both raw and normalized values were used for developing the models and it was found that the computational time and error will be reduced by normalized values.

Identification of the neuron's number in the input and output layers is normally a simple task dictated by the input and output variables considered to model the physical process (Bateni et al. 2007). The selected input parameters were depth of ambient water $(\mathrm{H})$, ambient current (Ua), velocity of the effluent discharge $\left(\mathrm{U}_{0}\right)$ and width of an equivalent slot diffuser (B). It 
Table 1: Range of different input parameters and initial dilutions used for modeling

\begin{tabular}{ll}
\hline Parameter & Range \\
\hline Ambient water depth $(\mathrm{H})$ & $9-26(\mathrm{~cm})$ \\
Ambient velocity (Ua) & $0.09-21.4(\mathrm{~cm} / \mathrm{s})$ \\
Discharge velocity $\left(\mathrm{U}_{0}\right)$ & $32.1-104.1(\mathrm{~cm} / \mathrm{s})$ \\
Width of an equivalent slot diffuser $(\mathrm{B})$ & $0.0133-0.0375(\mathrm{~cm})$ \\
Observed initial dilution $(\mathrm{S})$ & $8-33.3$ \\
\hline
\end{tabular}

Table 2: Error measures of different networks used with 15,000 iterations

\begin{tabular}{ccrcc}
\hline $\begin{array}{c}\text { Number of } \\
\text { neurons in } \\
\text { first layer }\end{array}$ & $\begin{array}{c}\text { Number of } \\
\text { neurons in } \\
\text { second layer }\end{array}$ & MSE & Bias & R \\
\hline 4 & - & 2.7 & 0.77 & 0.964 \\
5 & - & 2.7 & 0.68 & 0.961 \\
6 & - & 2.59 & 0.71 & 0.964 \\
7 & - & 2.8 & 0.74 & 0.959 \\
9 & - & 1.62 & 0.61 & 0.967 \\
4 & 2 & 2.7 & 0.68 & 0.962 \\
8 & 4 & 2.87 & 0.77 & 0.962 \\
12 & 8 & 2.5 & 0.68 & 0.965 \\
\hline
\end{tabular}

Table 3: Error measures of ANN, empirical and theoretical approaches

\begin{tabular}{lccc}
\hline & ANN & $\begin{array}{c}\text { Adams } \\
(1982)\end{array}$ & $\begin{array}{l}\text { Adams and } \\
\text { Stolzenbach (1977) }\end{array}$ \\
\hline MSE & 1.62 & 70.26 & 15510 \\
Bias & 0.61 & -6.05 & -61.92 \\
R & 0.967 & 0.20 & 0.01 \\
\hline
\end{tabular}

Table 4: Error measures of different networks, no $\mathrm{H}$

\begin{tabular}{lcrrr}
\hline $\begin{array}{c}\text { Number of } \\
\text { neurons in } \\
\text { first layer }\end{array}$ & $\begin{array}{c}\text { Number of } \\
\text { neurons in } \\
\text { second layer }\end{array}$ & MSE & Bias & R \\
\hline 5 & - & 2.41 & 0.94 & 0.959 \\
7 & - & 2.33 & 0.96 & 0.96 \\
9 & - & 2.38 & 1 & 0.959 \\
3 & 2 & 2.54 & 0.89 & 0.956 \\
6 & 3 & 2.24 & 0.93 & 0.962 \\
9 & 3 & 2.57 & 0.9 & 0.956 \\
9 & 6 & 2.5 & 0.98 & 0.956 \\
\hline
\end{tabular}

Table 5: Error measures of different networks, no Ua

\begin{tabular}{cccrr}
\hline $\begin{array}{c}\text { Number of } \\
\text { neurons in } \\
\text { first layer }\end{array}$ & $\begin{array}{c}\text { Number of } \\
\text { neurons in } \\
\text { second layer }\end{array}$ & MSE & Bias & R \\
\hline 3 & - & 2.25 & 0.84 & 0.96 \\
6 & - & 2.29 & 0.78 & 0.959 \\
9 & - & 2.34 & 0.73 & 0.958 \\
12 & - & 2.32 & 0.717 & 0.957 \\
3 & 2 & 2.39 & 0.94 & 0.959 \\
6 & 3 & 2.36 & 0.93 & 0.959 \\
9 & 3 & 2.25 & 0.85 & 0.959 \\
\hline
\end{tabular}

Table 6: Error measures of different networks, no $\mathrm{U}_{0}$

\begin{tabular}{cccrc}
\hline $\begin{array}{c}\text { Number of } \\
\text { neurons in } \\
\text { first layer }\end{array}$ & $\begin{array}{c}\text { Number of } \\
\text { neurons in } \\
\text { second layer }\end{array}$ & MSE & Bias & R \\
\hline 3 & - & 1.68 & 0.75 & 0.969 \\
6 & - & 1.74 & 0.73 & 0.968 \\
9 & - & 1.68 & 0.7 & 0.968 \\
3 & 2 & 1.87 & 0.76 & 0.965 \\
6 & 3 & 1.69 & 0.73 & 0.968 \\
\hline
\end{tabular}

Table 7: Error measures of different networks, no B

\begin{tabular}{ccrrr}
\hline $\begin{array}{c}\text { Number of } \\
\text { neurons in } \\
\text { first layer }\end{array}$ & $\begin{array}{c}\text { Number of } \\
\text { neurons in } \\
\text { second layer }\end{array}$ & MSE & Bias & $\mathrm{R}$ \\
\hline 3 & - & 4.23 & 0.46 & 0.872 \\
6 & - & 4.45 & 0.46 & 0.866 \\
9 & - & 4.5 & 0.47 & 0.865 \\
3 & 2 & 4.67 & 0.44 & 0.854 \\
6 & 3 & 4.55 & 0.48 & 0.86 \\
9 & 3 & 4.44 & 0.49 & 0.866 \\
12 & 3 & 4.38 & 0.5 & 0.869 \\
12 & 6 & 4.36 & 0.45 & 0.868 \\
\hline
\end{tabular}

Table 8: Comparison of error estimates of the networks with different input parameters

\begin{tabular}{lccc}
\hline Method & MSE & Bias & R \\
\hline ANN with all input & 1.62 & 0.61 & 0.967 \\
ANN no H & 2.24 & 0.93 & 0.962 \\
ANN no Ua & 2.25 & 0.84 & 0.960 \\
ANN no U & 1.68 & 0.7 & 0.968 \\
ANN no B & 4.23 & 0.46 & 0.872 \\
\hline
\end{tabular}

should be mentioned that angle between the port and sea bed and density difference were constant in the used data set. Hence, these parameters were not used as the input variables.

Different networks were examined and the network with one hidden layer and nine nodes was found to be optimal with minimum error. The error measures of different networks are shown in Table 2. As seen the network performs well and can be used successfully for prediction of initial dilution with an ARE of $7.68 \%$ and a correlation coefficient of 0.967 . Fig. 2 displays the comparison between measured and predicted initial dilution using the developed ANN model for both training and validation procedures. As shown, the used model has a higher training error compared with that of verification. The error in training can be reduced by increasing the number of iterations (Fig. 3). However, care should be taken not to over increase the number of iteration since the model can be over trained in this 

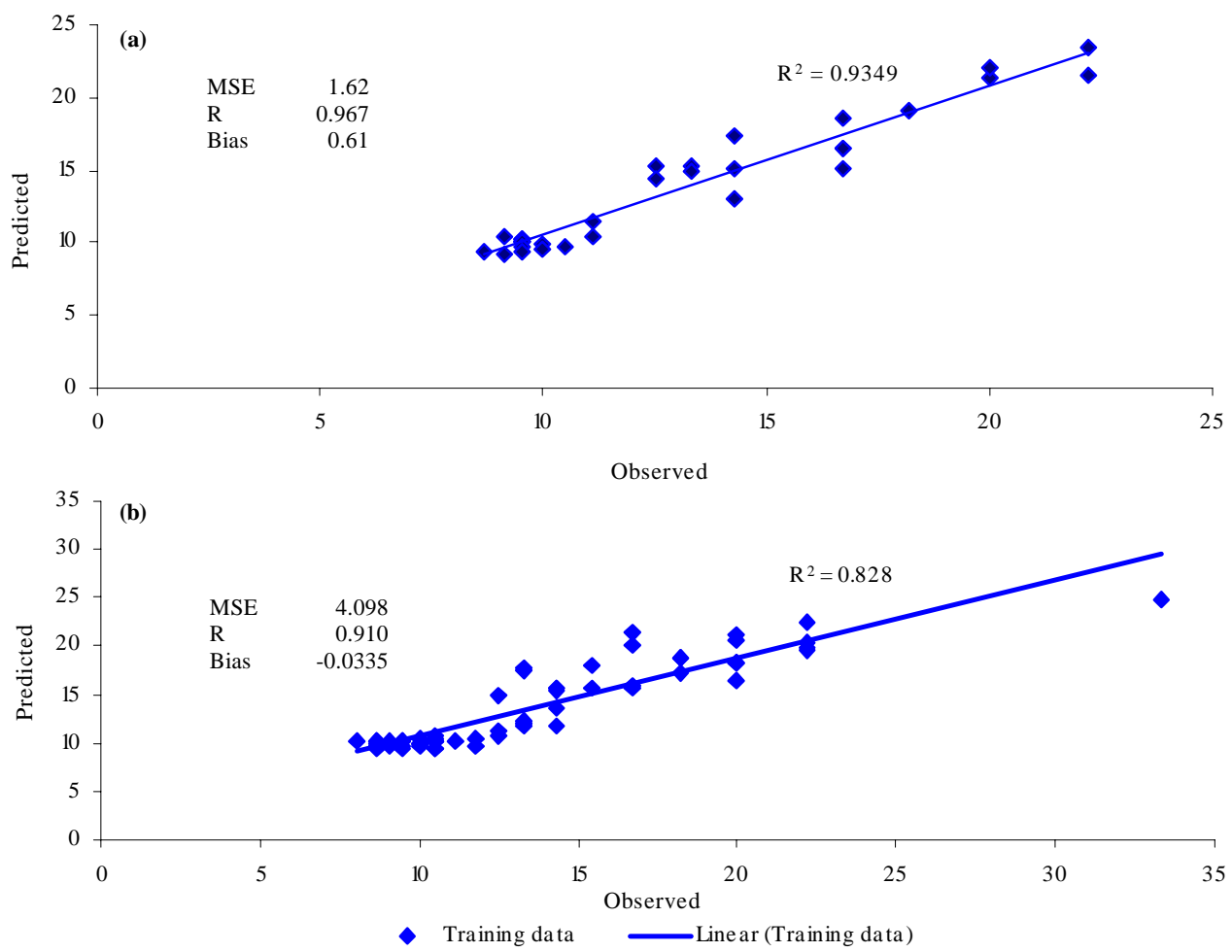

Fig. 2: Comparison of observed and predicted dilutions using ANN model with 15000 iteration (a) validation and (b) training
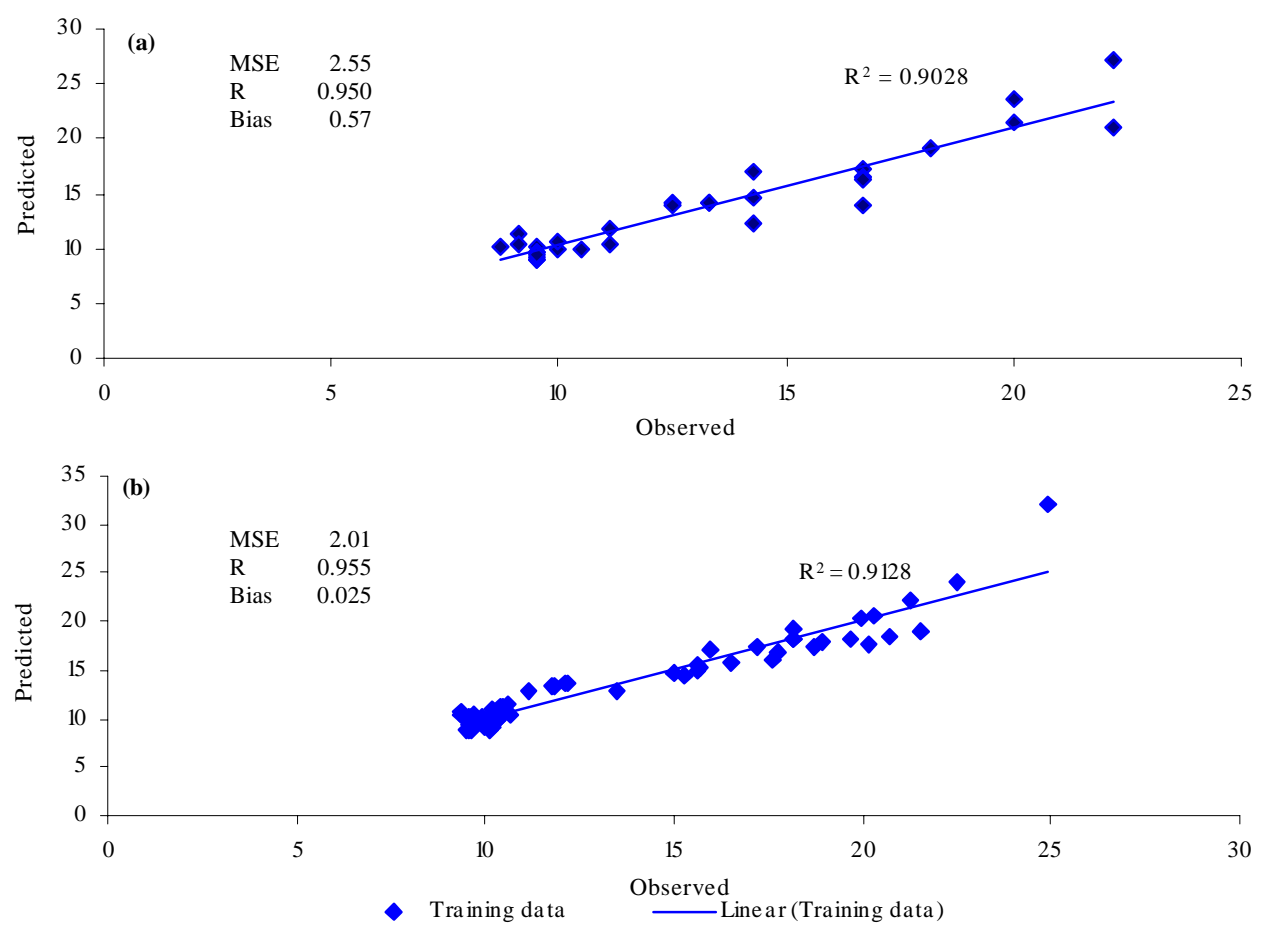

Fig. 3: Comparison of observed and predicted dilutions using ANN model with 1000000 iteration (a) validation and (b) training 
case. The criterions for stopping the iteration are generally reaching to a predefined level of accuracy or number of iterations. These are determined based on the speed of the calculations or experience of the modeler. The potential consequence of over-training is that the model's performance improves in the training phase while it performs poor in the testing phase. In this case, the model is called to be over-trained / overfitted and loses its generalization ability. The performance of the developed model is also compared to the theoretical model of Adams $(1972,1982)$ and empirical equation of Adams and Stolzenbach (1977) in Table 3. The theoretical model of Adams $(1972,1982)$ for dilution is based on the Bernoulli's and momentum equations and implies that the initial dilution is a linear function of Momentum ratio. The reason for selecting it for comparison was that it is the most recent theoretical model for estimation of initial dilution. This model is suggested by Lee et al. (1977) for estimation of dilution.

The suggested new approach predicts that initial dilution is more accurate and superior to both theoretical and empirical models. As discussed by Seo et al. (2001), these theoretical and empirical models are developed for special flow conditions and are not applicable for tee diffusers generally. It is interesting to analyze the sensitivity of the initial dilution to the different used input parameters. In this way, the relative importance of each parameter can be assessed as well. Following Bateni et al. (2007), the sensitivity analysis was conducted by ignoring one of the input parameters in each network. Tables $4-7$ show the error estimates obtained by ignoring different parameters. Here, different networks were tested to obtain the optimum structure. These tables show that the results are more sensitive to the ignored parameters than the structure of the network. In addition, Table 8 indicates that between the used parameters, the most important parameters is $B$, the width of the equivalent slot.

\section{CONCLUSION}

In this study, development and application of an ANN model for prediction of the initial dilution were outlined. The networks were trained using error back propagation algorithm with different structures. The collected laboratory data for a tee diffuser was manipulated to train and validate different networks. Results were compared with a different set of measurements and it was shown that the used ANN model is skillful in predicting the initial dilution. The results of the ANN model were also compared with those of empirical models, showing the superiority of the ANN approach. The obtained correlation coefficient between measured and predicted initial dilution using a three layer network with 9 neurons in the hidden layer was 0.97 . Furthermore, the relative importance of input variables were analyzed and it was shown that the width of the equivalent slot diffuser and the depth of ambient water are the most important parameters while the ambient current has the least effect on the initial dilution.

\section{ACKNOWLEDGEMENTS}

This study was partially supported by the COE in Hydro-Environmental Research, Iran University of Science and Technology.

\section{REFERENCES}

Abbaspour, M.; Javid, A. H.; Moghimi, P.; Kayhan, K., (2005). Modeling of thermal pollution in coastal area and its economical and environmental assessment. Int. J. Environ. Sci. Tech., 2 (1), 13-26 (13 pages).

Adams, E. E., (1972). Submerged Multiport Diffusers in Shallow Water with Current. M.Sc. Thesis, MIT, Cambridge, Massachusetts.

Adams, E. E., (1982). Dilution analysis for unidirectional diffusers. J. Hydraul. Eng-ASCE., 108 (HY3), 327-342 (13 pages).

Adams, E. E.; Stolzenbach, K., (1977). Comparison of alternative diffuser designs for the discharge of heated water into shallow receiving water. In Conference on waste heat management and utilization. Florida, USA. 171-189 (19 pages).

Akar, P. J.; Jirka, G. H., (1991). CORMIX2: An expert system for hdrodynamic mixing zone analysis of conventional and toxic multiport diffuser discharges. U.S. Environmental Protection Agency, Athens, Ga., EPA/600/3-91/073.

Alesheikh, A. A.; Ghorbanali, S. A.; Nouri, N., (2007). Coastline change detection using remote sensing. Int. J. Environ. Sci. Tech., 4 (1), 61-66 (6 pages).

Bateni, S. M.; Borghei, S. M.; Jeng, D. S., (2007). Neural network and neuro-fuzy assessments for scour depth around bridge piers. Eng. Appl. Artif. Intel., 20 (3), 401-414 (14 pages).

Cetin, M., (2009). A satellite based assessment of the impact of urban expansion around a lagoon. Int. J. Environ. Sci. Tech., 6 (4), 579-590 (12 pages).

Deo, M. C.; Kumar, N. K., (2000). Interpolation of wave heights. Ocean Eng., 27 (9), $907-919$ (13 pages).

Eberhart, R. C.; Dobbins, R. W., (1990). Neural network PS tools: A practical guide, Academic press, San Diego.

Elsayed, E. M., (1981). A thermal-hydraulic model investigation of submerged multi-port diffuser for offshore discharge of condenser-cooling water. Flow Systems Laboratory, Ontario Hydro, Toronto, Ontario, Report No. 81499 . 
Etemad-Shahidi, A.; Azimi, A. H., (2007). Simulation of thermal discharges using two mixing zone models. J. Coast. Res., SI 50, 658-662 (5 pages).

Etemad-Shahidi, A.; Azimi, A. H.; Hadjizadeh-Zaker, N., (2006). Numerical simulation of Boston outfall in stagnant ambient current. J. Coast. Res., SI 39 , 1520-1523 (4 pages).

Etemad-Shahidi, A.; Mahjoobi, J., (2009). Comparison between M5' model tree and neural networks for prediction of significant wave height in lake superior. Ocean Eng., 36 (15-16), 1175-1181 (7 pages).

Falconer, R., (1992). Flow and water quality modeling in coastal and inland waters. J. Hydro. Res., 30 (3), 437-452 (16 pages).

Fischer, H. B.; List, E. J.; Koh, R. C. H.; Imberger, J.; Brooks, N. H., (1979). Mixing in inland and coastal waters. Academic Press, New York, USA.

Grossberg, S., (1988). Nonlinear neural networks: Principle, mechanisms and architectures. Neural Networks, 1 (1), 1761 (45 pages).

Hamrick, J. M.; Mills, W. B., (2000). Analysis of water temperatures in conowingo pond as influenced by the peach bottom atomic power plant thermal discharge. Environ. Sci. Policy, 3 (1), 197-209 (13 pages).

Huang, W.; Foo, S., (2002). Neural network modeling of salinity variation in Apalachicola river. Water Res., 36 (1), 356362 (7 pages).

Karuppanapandian, T.; Karuppudurai, T.; Kumaraguru, A. K., (2007). A preliminary study on the environmental condition of the coral reef habitat. Int. J. Environ. Sci. Tech., 4 (3), 371-378 (8 pages)

Kazeminezhad, M. H.; Etemad-Shahidi, A.; Yeganeh-Bakhtiary, A., (2010). An alternative approach for investigation of the wave-induced scour around pipelines. J. Hydro., 12 (1), 51-65 (15 pages).

Kim, D. G.; Seo, I. W., (2000). Modeling the mixing of heated water discharged from a submerged multiport diffuser. J. Hydro. Res., 38 (4), 259-269 (11 pages).

Kuo, J.; Hsieh, M.; Lung, W.; She, N., (2007). Using artificial neural network for reservoir eutrophication prediction. Eco. Model., 200 (1-2), 171-177 (7 pages).

Lee, J. W.; Jirka, G. H.; Harleman, R. F., (1977). Modeling of unidirectional thermal diffusers in shallow waters. Rep. 228. MIT, Cambridge, Massachusetts.
Lee, J. H. W.; Cheung, V., (1990). Generalized lagrangian model for buoyant jets in current. J. Environ. Eng-ASCE, 116 (6), 1085-1105 (20 pages).

Mahjoobi, J.; Etemad-Shahidi, A.; Kazeminezhad, M., (2008). Hindcasting of wave parameters using different soft computing methods. Appl. Ocean Res., 30 (1), 28-36 (8 pages).

Maier, H. R.; Dandy, C. G., (2000). Neural network for the prediction and forecasting of water resources variables: A review of modeling issues and applications. Environ. Model. Softw., 15 (1), 101-124 (24 pages).

McCulloch, W. S.; Pitts, W., (1943). A logical calculus of the ideas immanent in nervous activity. Math. Biophys., 5 (1), 115-133 (19 pages).

Muttiah, R. S.; Srinivasan, R.; Allen, P. M., (1997). Prediction of two-year peak stream discharges using neural networks. J. Am. Water Resour. As., 33 (3), 625-630 (6 pages).

Nouri, J.; Karbassi. A. R.; Mirkia, S., (2008). Environmental management of coastal regions in the Caspian Sea. Int. J. Environ. Sci. Tech., 5 (1), 43-52 (10 pages).

Öztürk, I.; Sarikaya, H. Z.; Aydin, A. F.; Demir, I., (1995). A simplified model for thermal discharges. Water Sci. Tech., 32 (2), 183-191 (9 pages).

Palani, S.; Liong, S.; Tkalich, P., (2008). An ANN application for water quality forecasting. Mar. Pollut. Bul., 56 (9), 15861597 (12 pages).

Rumelhart, D. E.; Hinton, G. E.; Williams, R. J., (1986). Learning representations by back-propagating errors. Nature, 323, 533-536 (4 pages).

Seo, I. W.; Kim, H.; Yu, D.; Kim, D., (2001). Performance of Tee diffusers in shallow water with cross flow. J. Hydro. Res., 127, 53-61 (9 pages).

Suen, J.; Eheart, W., (2003). Evaluation of neural networks for modeling nitrate concentrations in rivers. J. Water Res., Pl-ASCE, 129 (6), 505-510 (6 pages).

Suh, S. W., (2001). A hybrid near-field/far-field thermal discharge model for coastal areas. Mar. Pollut. Bul., 43 (712), 225-233 (9 pages).

Yeh, Y. C.; Kuo, Y. H.; Hsu, D. S., (1993). Building KBSE for diagnosing PC piles with artificial neural networks. J. Comput. Civil Eng., 7 (1), $71-93$ (23 pages).

\begin{abstract}
AUTHOR (S) BIOSKETCHES
Etemad-Shahidi, A., Ph.D., Associate Professor, School of Civil Engineering, Iran University of Science and Technology, Tehran, Iran. P.O Box:16765-163, Email: etemad@iust.ac.ir

Zoghi, M. J., M.Sc., School of Civil Engineering, Iran University of Science and Technology, Tehran, Iran. P.O. Box: 16765-163, Email: mzoghi@civil.iust.ac.ir

Saeedi, M., Ph.D., Assistant Professor, School of Civil Engineering, Iran University of Science and Technology, Tehran, Iran. P.O. Box: 16765-163, Email: msaeedi@iust.ac.ir
\end{abstract}

How to cite this article: (Harvard style)

Etemad-Shahidi, A.; Zoghi, M. J.; Saeedi, M., (2010). An alternative data driven approach for prediction of thermal discharge initial dilution using tee diffusers. Int. J. Environ. Sci. Tech., 7 (1), 29-36. 